\title{
FLUTUAÇÃO SAZONAL DE AFÍDEOS E SEUS PREDADORES EM CULTURA DE ALFAFA
}

Suzan Beatriz Zambon da Cunha ${ }^{1}$, Carlos Roberto Sousa e Silva ${ }^{1}$, Evoneo Berti-Filho ${ }^{2}$

${ }^{1}$ Universidade Federal de São Carlos (UFSCar), E-mail: suzanbio@yahoo.com.br, dcrs@ufscar.br

${ }^{2}$ Universidade de São Paulo, Escola Superior de Agricultura Luiz de Queiroz (ESALQ), E-mail: eberti@usp.br

\section{RESUMO}

Estudou-se a influência de temperatura, precipitação, umidade e vento, e o controle exercido por predadores na flutuação sazonal dos afídeos Acyrthosiphon pisum, Acyrthosiphon kondoi, Aphis craccivora e Therioaphis trifolli em cultura de alfafa na região de São Carlos, SP. A. pisum foi o afídeo predominante na cultura no período avaliado, agosto de 2011 a julho de 2012. Nenhuma das variáveis ambientais influenciou significativamente a flutuação sazonal de afídeos. O manejo dos cortes na cultura e as ações predatórias foram os principais responsáveis pelas variações na dinâmica populacional desses insetos. Dentre os predadores, os coccinelídeos foram os mais abundantes e Harmonia axyridis a espécie mais coletada.

Palavras-chave: Aphidoidea, Coccinelídeos, Medicago sativa

\section{SEASONAL FLUCTUATION OF APHIDS AND THEIR PREDATORS IN ALFALFA CROP}

\section{ABSTRACT}

This paper deals with the influence of temperature, precipitation, humidity and wind, and the control exercised by predators in the seasonal fluctuation of the aphids Acyrthosiphon pisum, Acyrthosiphon kondoi, Aphis craccivora and Therioaphis trifolii in alfalfa crop in the region of São Carlos, State of São Paulo, Brazil. During the period of August 2011 to July 2012, the most predominant aphid was A. pisum. Environmental variables have no significant influence on the seasonal fluctuation of aphids. The management of the cuts in the culture and the predatory actions were responsible for variations in population dynamics of these insects. Among the predators, coccinellids were the most abundant ones and Harmonia axyridis the most collected species.

Keywords: Aphidoidea, Coccinellids, Medicago sativa 


\section{INTRODUÇÃO}

Os afídeos Acyrthosiphon pisum; A. kondoi, Therioaphis trifolli e Aphis craccivora (Hemiptera: Aphidoidea) são pragas frequentes em plantações de alfafa no Brasil, relatados por diversos autores (OLIVEIRA et al., 1986; KALVELAGE, 1990; LÁZZARI et al., 1996; SOUSASILVA et al., 1998; BUENO \& SILVA, 2008). Ataques intensos desses insetos às plantas acarretam o encurtamento dos internódios e o encarquilhamento das folhas, prejudicando o crescimento desta forrageira (AFONSO, 2008). Além dos danos diretos, estes insetos podem causar danos indiretos com a transmissão de vírus às plantas. $A$. pisum, $T$. trifolli e A. craccivora são vetores do vírus do mosaico da alfafa, um dos principais vírus da cultura. T. trifolli também é vetor do "clover (red) vein mosaic" e A. craccivora é vetor do vírus das enações (SOUSA-SILVA et al. 1998).

Segundo Lázzari e Lazzarotto (2005), o estabelecimento e desenvolvimento das populações de afideos são influenciados pela disponibilidade e qualidade do alimento, ação reduzida de agentes de controle biológico e condições climáticas favoráveis. Os fatores climáticos afetam suas populações, podendo reduzi-las ou aumentálas. A flutuação sazonal dos afideos também está relacionada com o hábito alimentar da espécie. Espécies polífagas, capazes de se alimentar de diversas plantas hospedeiras, podem ser favorecidas ao longo de todo o ano, podendo apresentar períodos de maior ou menor incidência, enquanto outras podem ocorrer em apenas uma determinada época.

O presente trabalho teve como objetivo estudar a influência de temperatura, da precipitação, umidade do ambiente e do vento e avaliar a influência dos predadores e do manejo dos cortes da cultura na flutuação sazonal dos afídeos da alfafa.

\section{MATERIAL E MÉTODOS}

O trabalho foi desenvolvido na Unidade da Embrapa Pecuária Sudeste CPPSE, situada no município de São Carlos, SP. As coletas dos afídeos e seus predadores foram realizadas a cada 10 dias, no período de agosto de 2011 a julho de 2012, num total de 36 amostragens em uma área de $3.000 \mathrm{~m}^{2} \mathrm{de}$ alfafa, cv. Crioula, com espaçamento entre as fileiras de $90 \mathrm{~cm}$. Foram estabelecidos oito pontos aleatórios para coleta, caminhando-se em zigue-zague pela cultura. Em cada ponto uma planta foi selecionada ao acaso e sua haste foi vigorosamente agitada dentro de uma bandeja. Os insetos desprendidos das hastes foram coletados, acondicionados em frascos, e posteriormente, triados, 
identificados e contados sob microscópio estereoscópico.

Os dados das variáveis climáticas foram obtidos através do site do Centro Nacional de Pesquisa Pecuária Sudeste da Embrapa, São Carlos, SP (EMBRAPA, 2012). Estas variáveis foram relacionadas com as populações de afídeos mediante análise de correspondência canônica (CCA), feita por meio do aplicativo Canoco (TER BRAAK, 1988).

Os dados da flutuação populacional de predadores foram correlacionados com a flutuação populacional de afídeos em teste de correlação linear.

\section{RESULTADOS E DISCUSSÃO}

De agosto de 2011 a julho de 2012 foram coletados 15.562 afídeos e 2.161 predadores. Dentre os afídeos, A. pisum foi a espécie de maior abundância, 37,28\% do total coletado. O maior pico populacional da espécie, com 2148 indivíduos, ocorreu em março de 2012. A temperatura média no período foi de $22,2^{\circ} \mathrm{C}$, a precipitação de $42,2 \mathrm{~mm}$ e umidade relativa de $78,5 \%$. O menor número de indivíduos, 29, foi registrado em julho de 2012, com a temperatura média a $16,7^{\circ} \mathrm{C}$, precipitação de $34,6 \mathrm{~mm}$ e umidade de $76,3 \%$. T. trifolii representou 30,48\%, com o maior pico populacional em março de 2012, totalizando 1587 indivíduos. A temperatura média no período foi de $22,2^{\circ} \mathrm{C}$, a precipitação mensal de $42,2 \mathrm{~mm}$ e umidade relativa de $78,5 \%$. $\mathrm{O}$ menor número de indivíduos, 18 , ocorreu em janeiro de 2012 a $20,9^{\circ} \mathrm{C}$, precipitação mensal de $360,4 \mathrm{~mm}$ e umidade relativa de $85,3 \%$. $A$. craccivora correspondeu a 16,51\% com o maior pico populacional observado em fevereiro de 2012, com um total de 1361 indivíduos. A temperatura média no período foi de $23,2^{\circ} \mathrm{C}$, a precipitação de $152,8 \mathrm{~mm}$ e umidade relativa de 77,4\%. Em setembro de 2011 nenhum indivíduo da espécie foi coletado. A temperatura média no período foi de $20,6^{\circ} \mathrm{C}$, a precipitação de $4,4 \mathrm{~mm}$ e a umidade relativa de 55,3\%. Para A. kondoi o maior pico populacional, com um total de 921 indivíduos foi observado no início de março de 2012 , com a temperatura média de $22,2^{\circ} \mathrm{C}$, precipitação de $42,2 \mathrm{~mm}$ e umidade relativa de 78,5\%. O menor número de indivíduos, 14, foi observado em outubro de 2011. A temperatura média no período foi de $24^{\circ} \mathrm{C}$, a precipitação de $0,2 \mathrm{~mm}$ e umidade de $57,2 \%$. A. kondoi foi a espécie de menor abundância representando $15,17 \%$ dos afídeos coletados (Figura1). 


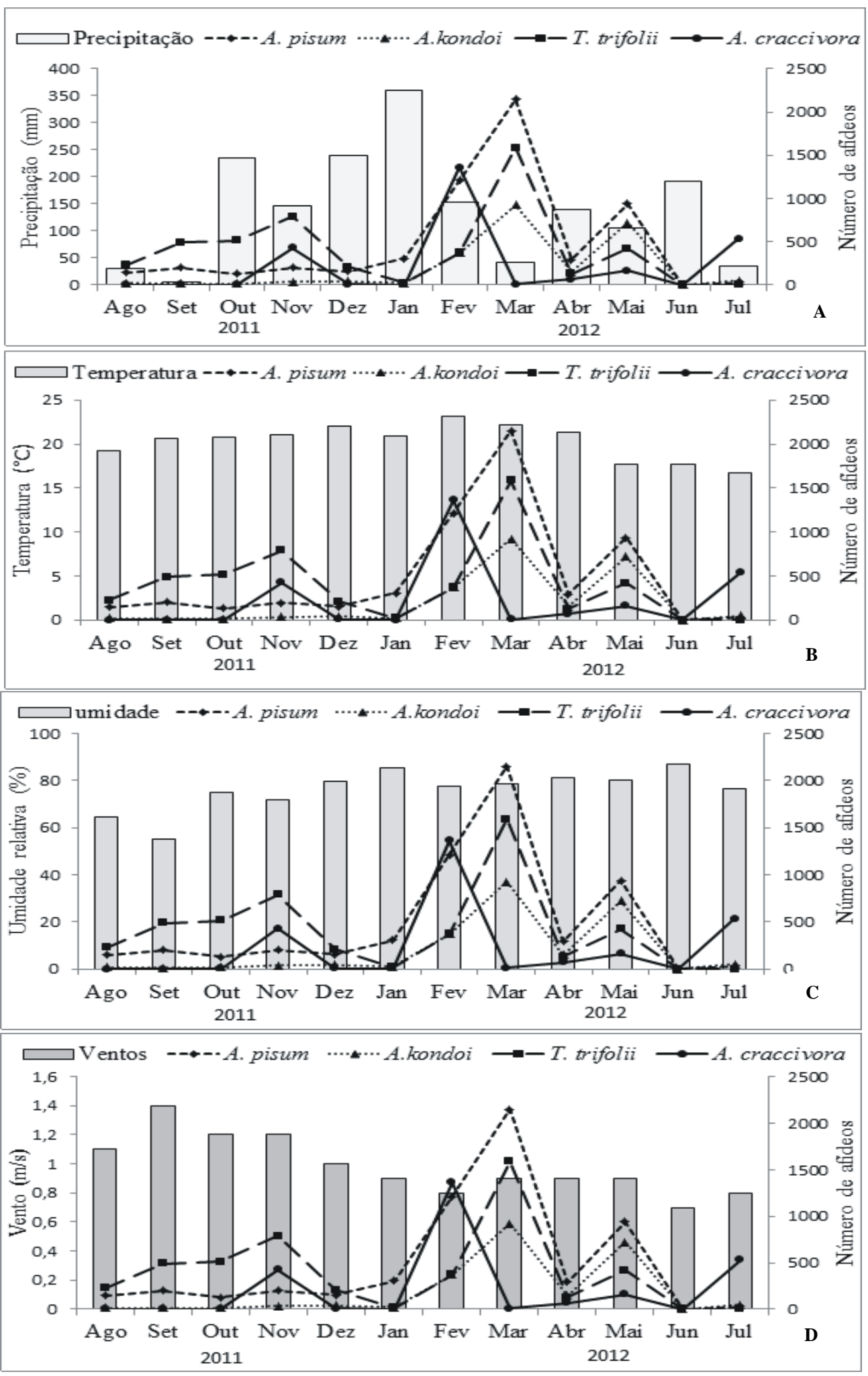

Figura 1. Correlação entre as densidades populacionais dos afídeos T. trifolli, A. craccivora, A. pisum e $A$. kondoi em cultura de alfafa na região de São Carlos, SP, no período de agosto de 2011 a julho de 2012, e as variáveis climáticas: A) precipitação; B) temperatura; C) umidade relativa; D) ventos. 
Nenhum afídeo e nem qualquer um de seus inimigos naturais foi observado no mês de junho, provavelmente devido ao controle fitossanitário da cultura ao final do mês de maio. No mês seguinte, em julho de 2012, observou-se a reinfestação da cultura, primeiramente por A. craccivora e posteriormente por $A$. pisum seguido de $A$. kondoi. De junho de 2012 até o final das amostragens, em julho de 2012 nenhum exemplar de T. trifolli foi coletado.

Considerando-se o número total de afídeos, em 2012, a menor quantidade coletada, 349, foi em janeiro, quando as plantas de alfafa encontravam-se senescentes. Nesse período a temperatura média foi de $20,9^{\circ} \mathrm{C}$, precipitação mensal de $360,4 \mathrm{~mm}$ e umidade relativa do ar de $85,3 \%$. Dois picos populacionais foram observados, sendo o maior, no mês de março, com 4665 indivíduos coletados. Neste mês a temperatura média foi de $22,2^{\circ} \mathrm{C}$, precipitação de $42,2 \mathrm{~mm}$ e umidade relativa de 78,5\%. Um segundo pico de 2236 afídeos ocorreu em maio, com a temperatura média em $17,7^{\circ} \mathrm{C}$, precipitação de $106,2 \mathrm{~mm}$ e umidade relativa de $80,3 \%$ (Figura 1A), contudo, nenhuma das variáveis ambientais estudadas influenciou significativamente a flutuação sazonal dos afídeos, de acordo com os resultados observados no diagrama de ordenação da CCA.

Dos 2.161 predadores de afídeos coletados na alfafa, os coccinelídeos (Coleoptera: Coccinellidae) representaram 68,24\%. Harmonia axyridis foi a espécie mais abundante $(53,27 \%)$, seguida de Hippodamia convergens $(29,13 \%)$ e Cycloneda sanguinea $(15,17 \%)$.

Eriopis connexa e Coleomegilla maculata juntas representaram $2,41 \%$ do total. O pico populacional para $H$. axyridis foi observado em março de 2012 totalizando 362 indivíduos (Figura 2B). H. convergens e $C$. sanguinea foram as espécies mais constantes na cultura durante o período de coleta, ambas apresentando o maior pico populacional em maio de 2012 com 101 e 71 indivíduos coletados, respectivamente (Figura $2 \mathrm{C}$ e D). O pico populacional de coccinelídeos ocorreu logo após o pico populacional de afídeos (Figura 2A), mostrando o padrão típico da relação predador/presa $(r=0,6756, t=3,0390$, $\mathrm{p}=0,0112$ ). 


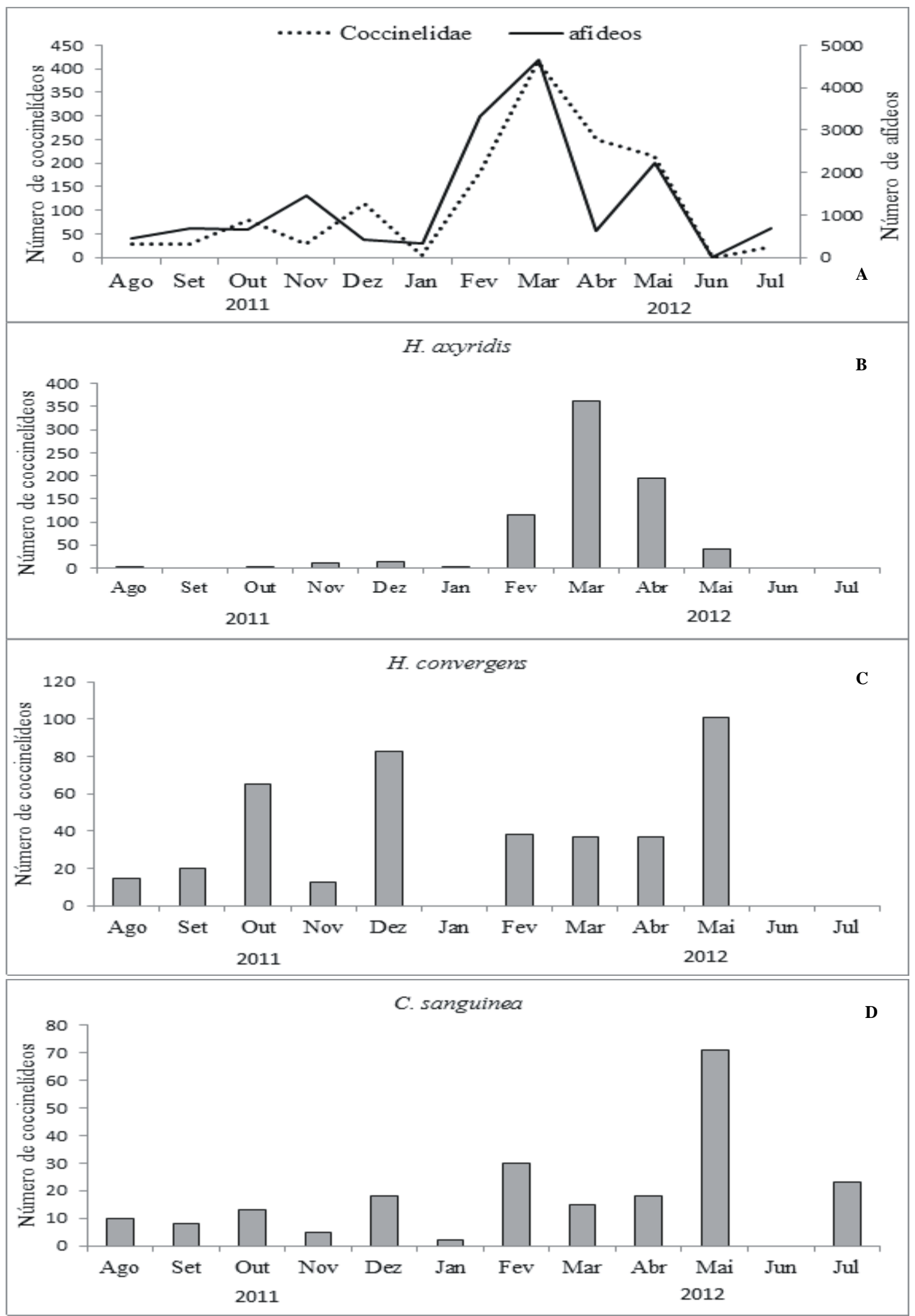

Figura 2. Dados da flutuação populacional de: A) total de afídeos e total de coccinelídeos. B) $H$. axyridis, C) $H$. convergens e D) C. sanguinea na cultura de alfafa em São Carlos, SP no período de agosto de 2011 a julho de 2012. 
$\mathrm{Na}$ área estudada, as flutuações sazonais de $A$. kondoi e A. pisum foram muito semelhantes, com picos populacionais no mesmo período, diferenciando-se pelo número de afídeos amostrados (Figura 1), fato observado também por Mendes et al. (2000) e Carvalho et al. (1996) ambos em MG, e por Silva et al. (2007) em SP. Estes autores observaram que a população de $A$. kondoi foi maior que a de A. pisum, diferentemente do observado neste trabalho, cuja população de A. pisum foi o dobro da população de $A$. kondoi.

Em relação à análise estatística, Rakhshani et al. (2009), em estudo realizado em campos de alfafa no Irã, também salientaram que nenhuma relação significativa foi observada entre a abundância dos afídeos $A$. pisum, A. craccivora e $T$. trifolli com a precipitação e a umidade, como observado também neste trabalho. No entanto relataram que a temperatura pode ser um fator importante, pois observaram em laboratório que temperaturas acima de $25^{\circ} \mathrm{C}$, ou abaixo de $12^{\circ} \mathrm{C}$ causaram a redução dos afídeos, de maneira geral.

No campo, um fator importante para a redução das infestações de afídeos é o processo de cortes da cultura. Carvalho et al. (1997) estudaram a influência dos cortes da alfafa na dinâmica populacional das espécies de afídeos em Lavras, MG, e observaram que cada corte reduziu a densidade populacional das espécies e que a gradativa elevação nos níveis populacionais foi condicionada ao rebrote das plantas e aos fatores climáticos.

$\mathrm{Na}$ alfafa, apenas uma semana após os cortes já ocorre o aparecimento dos brotos e os afídeos começam a recolonizar a cultura. Estes autores, em trabalho anterior (1996), relataram que a influência dos cortes na dinâmica populacional dos afídeos depende de como são feitos. Citam o corte realizado em faixas, onde permanecem ainda plantas de vários ciclos de crescimento na cultura e o corte total que acaba deixando o solo livre de vegetação, como observado no presente trabalho. De acordo com Bosch et al. (1967) o corte total é eficaz, pois reduz o alimento para os afídeos e cria condições climáticas desfavoráveis aos insetos como um todo, devido a incidência direta da radiação solar no campo.

Harper et al. (1990) observaram que A. pisum tem capacidade de recuperação muito rápida quando são efetuados cortes totais na cultura, mais do que em outros tipos de corte. Nesses casos, as populações de $A$. pisum recuperam-se em duas semanas e continuam a aumentar, fato também observado no presente trabalho. Segundo Carvalho et al. (1996) A. pisum pode atingir 
níveis populacionais muito mais altos após os cortes do que os observados antes dos cortes. Na cultura analisada, foram coletados 157 indivíduos de $A$. pisum uma semana antes do corte da alfafa, realizado em fevereiro; duas semanas após o corte foram coletados 472 indivíduos, e 1152 indivíduos foram coletados cinco semanas após o corte. Posteriormente a população decresceu novamente. Antes do segundo corte, realizado em abril, foram coletados 51 exemplares de A. pisum. O número de indivíduos coletados aumentou gradativamente, atingindo 568 indivíduos três semanas após o corte.

Rakhshani et al. (2009) citam que após os cortes na alfafa, o número de inimigos naturais diminui drasticamente, favorecendo uma rápida recolonização da cultura pela praga, fato também observado neste trabalho onde os predadores de maneira geral começaram a aumentar, quatro semanas após os cortes em fevereiro e três semanas após os cortes em maio, quando havia grande oferta de alimento. Esta condição, aliada ao número reduzido de predadores, favoreceu $\mathrm{o}$ desenvolvimento populacional dos afídeos, reduzindo-se, posteriormente, pela senescência da cultura e pelo aumento do número de predadores.

\section{CONCLUSÕES}

Na cultura de alfafa na região de São Carlos, SP, no período de agosto de 2011 a julho de 2012, o afídeo predominante é $A$. pisum e o predador predominante é coccinelídeo $H$. axyridis;

De acordo com a análise de correspondência canônica, em condições de campo, nenhuma das variáveis ambientais influencia significativamente a flutuação populacional de afídeos;

Os cortes da alfafa no início do mês de fevereiro e em meados do mês de abril propiciam o aparecimento de brotos e folhas novas nas plantas e isso favorece o aumento populacional dos afídeos;

As populações de coccinelídeos e de afídeos seguem o padrão típico da relação predador-presa;

A presença de inimigos naturais e o manejo de cortes da cultura são os fatores que mais influenciam a dinâmica populacional dos afídeos.

\section{AGRADECIMENTOS}

Ao Conselho Nacional de Desenvolvimento Científico e Tecnológico (CNPq) pelo apoio financeiro

\section{REFERÊNCIAS}

AFONSO, A. P. S. 2008. Insetos pragas da alfafa. In: MITTELMANN, A.; LEDO, F. 
J. S.; GOMES, J.F. Tecnologias para produção de alfafa no Rio Grande do Sul. EMBRAPA - Centro de Pesquisa Agropecuária de Clima Temperado, Juiz de Fora, p.18-33.

BOSCH, R.V.D.; LAGACE, C.F.; STERN, V.M. 1967. The interrelationship of the aphid Acyrthosiphon pisum, and its parasite, Aphidius smithi, in a stable environment. Ecology, Washington, v. 48, n.6, p. 993-1000.

BUENO, V. H.P.; SILVA, A.C. 2008. Pragas na cultura de alfafa. In: FERREIRA, R. P.; RASSINI, J. B.; RODRIGUES, A. A.; FREITAS, A. F.; CAMARGO, A. C.; MENDONÇA, F. C. Cultivo e utilização da alfafa nos trópicos. São Carlos: Embrapa Pecuária Sudeste, p. 289-316.

CARVALHO, A. R.; BUENO, V. H. P.; MENDES, S. 1996. Influência de fatores climáticos e do corte na flutuação populacional de pulgões (Homoptera: Aphididae) na cultura da alfafa (Medicago sativa L.) em Lavras, MG. Pesquisa Agropecuária Brasileira, Brasília, v.31, n.5, p.317-324.

CARVALHO, A. R.; MENDES, S.; BUENO, V. H. P. 1997. Influência de cortes na cultura de alfafa (Medicago sativa) sobre a flutuação populacional de ninfas e adultos de pulgões (Homoptera: Aphididae). Anais da Sociedade Entomológica do Brasil, Londrina, v.26, n.2, p. 265-275, ago.

EMBRAPA. 2012. Empresa Brasileira de Pesquisa Agropecuária. Disponível em: <http://www.cppse.embrapa.br>. Acesso em: 2 ago/12.

HARPER, A. M.; SCHABER, B. D.; STORY, T. P.; ENTZ, T. 1990. Effect of swathing and clear-cutting alfalfa on insect populations in Southern Alberta. Journal of Economic Entomology, Oxford, v. 83, n.5, p.2050-2057.

KALVELAGE, H. 1990. Principais insetos que atacam a cultura da alfafa no Brasil. In: NUERNBERG, N. J.; MILAN, P. A.;
SILVEIRA, C. A. M. Manual de produção da alfafa. Florianópolis: Empresa Catarinense de pesquisa Agropecuária, p. 63-86.

LAZZARI, S. M.N.; CARVALHO, R. C. Z.; FURIATTI, R. S.; MELLO, M. E. F. 1996. The spotted alfalfa aphid, Therioaphis trifolli (Monell) f. maculata in Brazil: first record. Anais da Sociedade Entomológica do Brasil, Londrina,v.25, n.1, p. 153-155.

LAZZARI, S. M. N.; LAZZAROTTO, C. M. 2005. Distribuição altitudinal e sazonal de afídeos (Hemiptera, Aphididae) na serra do mar, Paraná, Brasil. Revista brasileira de Zoologia, Curitiba, v.22, n.4, p.891897.

MENDES, S.; CERVIÑO, M. N.; BUENO, V. H. P.; AUAD, A. M. 2000. Diversidade de pulgões e de seus parasitóides e predadores na cultura da alfafa. Pesquisa Agropecuária Brasileira, Brasília, v.35, n.7, p.1305-1310.

OLIVEIRA, P. R. D.; VENDRAMIM, J. D.; CORSI, M. 1986. Pulgão verde-azulado Acyrthosiphon kondoi Shinji, 1938 (Homoptera: Aphididae): uma nova praga da alfafa (Medicago sativa L.) no Brasil. Anais da Sociedade Entomológica do Brasil, Londrina, v.15, n.2, p. 397-398.

RAKHSHANI, H.; EBADI, R.; MAHAMMADI, A. A. 2009. Population dynamics of alfalfa aphids and their natural enemies, Isfahan, Iran. Journal of Agricultural Science and Technology, Tehran, v.11, p. 505-520.

SILVA, A. A.; VARANDA, E. M.; RASSINI, J. B. 2007. Weather, cultivar and density-dependent processes influence on aphid in alfalfa. Bragantia, Campinas, v.66, n.2, p.285-290.

SOUSA-SILVA, C. R.; PACHECO, J. M.; RASSINI, J. B.; ILHARCO, F. A. 1998. Afídeos da alfafa no Brasil (Homoptera, Aphidoidea). Revista Brasileira de Entomologia, Curitiba, v. 41, n. 2- 4 p. 285-288. 
TER BRAAK, C.J.F. 1988. Canoco- a Fortran program for canonical community ordination by (partial) (detrended) (canonical) correspondence analysis and redundancy analysis (version 2.1), Wageningen: Institute of Applied Computer Science.

Recebido em: 28/5/2016 Aceito para publicação em: 7/10/2016 